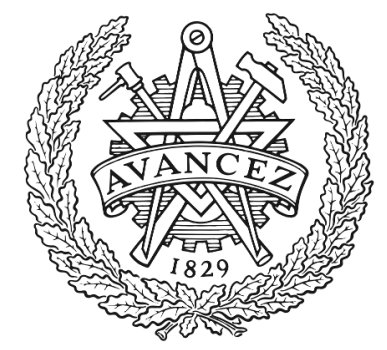

CHALMERS

UNIVERSITY OF TECHNOLOGY

\title{
Cooling capability of liquid nitrogen and carbon dioxide in cryogenic milling
}

Downloaded from: https://research.chalmers.se, 2023-04-26 06:51 UTC

Citation for the original published paper (version of record):

Pusavec, F., Grguraš, D., Koch, M. et al (2019). Cooling capability of liquid nitrogen and carbon dioxide in cryogenic milling. CIRP Annals - Manufacturing Technology, 68(1): 73-76.

http://dx.doi.org/10.1016/j.cirp.2019.03.016

N.B. When citing this work, cite the original published paper. 


\title{
Cooling capability of liquid nitrogen and carbon dioxide in cryogenic milling
}

\author{
Franci Pušavec ${ }^{\mathrm{a}, *}$, Damir Grguraša ${ }^{\mathrm{a}}$, Matthias Koch ${ }^{\mathrm{b}}$, Peter Krajnik (2) \\ ${ }^{a}$ University of Ljubljana, Faculty of Mechanical Engineering, Ljubljana, Slovenia \\ ${ }^{\mathrm{b}}$ RWTH Aachen University, Laboratory for Machine Tools and Production Engineering (WZL), Aachen, Germany \\ ${ }^{\mathrm{C}}$ Chalmers University of Technology, Department of Industrial and Materials Science, Gothenburg, Sweden
}

\section{A R T I C L E I N F O}

Keywords:

Cryogenic machining

Milling

Temperature

\begin{abstract}
A B S T R A C T
This paper discusses an investigation into the capability of liquid nitrogen $\left(\mathrm{LN}_{2}\right)$ and liquid carbon dioxide $\left(\mathrm{LCO}_{2}\right)$ as a coolant in machining. A comparative analysis of the heat-transfer rate was made utilizing cooling of a controlled heat source with an integrated temperature sensor. The analysis was coupled with experimental in-process temperature measurements in cryogenic milling of titanium alloy Ti-6Al-4V ( $(3)$. The results indicate that cooling capability differs between these two cryogenic media, in both the observed cooling rate as well as in the achieved steady-state temperature.
\end{abstract}

(c) 2019 Published by Elsevier Ltd on behalf of CIRP.

\section{Introduction}

Liquid nitrogen $\left(\mathrm{LN}_{2}\right)$ and liquid carbon dioxide $\left(\mathrm{LCO}_{2}\right)$ are the two most commonly used cryogenic media for machining applications [1]. However, the differences between $\mathrm{LN}_{2}$ and $\mathrm{LCO}_{2}$ in terms of delivery conditions into the cutting zone, as well as in their cooling capability (ability for heat extraction during the machining process), are not well understood. A quantitative measure of the ability of a cryogen to remove a certain amount of heat from the cutting zone refers to heat-transfer rate in Watts [2]. In previous studies, the cooling capability of cryogenic media was estimated via the determination of the heat-transfer coefficient between the cryogenic media and the workpiece surface. It was found that heat evacuation is proportional to the coefficient of heat transfer and the difference between the cryogenic media temperature and the contact surface temperature [3-6]. In addition, cooling capability was also estimated with temperature measurements during or after the machining process [7-10]. However, in observing the results, huge variations with contradictory trends can be observed. Furthermore, there is a lack of fundamental studies - employing a direct determination of the cooling capability of $\mathrm{LN}_{2}$ and $\mathrm{LCO}_{2}$, as well as their comparison in terms of the cooling rate and the achieved steady-state temperature - in comparison to conventional cooling with emulsion.

Considering this, an attempt is made to advance the understanding of the cooling heat-flow rate of $\mathrm{LN}_{2}$ and $\mathrm{LCO}_{2}$. Their cooling capabilities are compared with the cooling capability of standard conventional cooling with emulsion. First, heat-evacuation mechanisms for $\mathrm{LN}_{2}$ and

\footnotetext{
* Corresponding author.

E-mail address: franci.pusavec@fs.uni-lj.si (F. Pušavec).
}

$\mathrm{LCO}_{2}$ are briefly discussed, followed by a fundamental coolingcapability assessment using a controlled heat source with an integrated temperature sensor. With this method, it is possible to determine the cooling heat flow rate, expressed in Watts, for all coolants, as well as the maximum cooling rate, measured in ${ }^{\circ} \mathrm{C} / \mathrm{s}$. The experiments were verified via measurements of the in-process cutting temperature using embedded thermocouples in the cutting inserts during milling of titanium alloy Ti-6Al-4V $(ß)$.

\section{Heat-evacuation mechanisms}

In conventional machining (cooling with emulsion), an emulsion is delivered into the cutting zone at ambient temperature. In this situation, the heat evacuation mechanism, as well as related cooling capability, is largely dependent on the temperature difference. The sensible heat transfer rate, $Q^{\prime}{ }_{s}$, in $W$ is:

$Q ' s=\cdot c p \cdot\left(T m_{2}-T m_{1}\right)$

where is the media mass flow rate, in $\mathrm{kg} / \mathrm{s}, c_{p}$ the specific heat capacity, in $\mathrm{J} / \mathrm{kg} \mathrm{K} ; T_{\mathrm{m}_{-1}}$ the media temperature before entering the cutting zone, in ${ }^{\circ} \mathrm{C}$, and $T_{\mathrm{m} \_2}$ media temperature when leaving the cutting zone, in ${ }^{\circ} \mathrm{C}$. The $\mathrm{LN}_{2}$ is stored in the vacuum-insulated Dewar, usually under a pressure of 4 bar (0.4 MPa) and delivered through the insulated piping into the cutting zone at $-195.8^{\circ} \mathrm{C}$ $(77.35 \mathrm{~K})$. When the $\mathrm{LN}_{2}$ hits the higher-temperature workpiece surface, it evaporates from the contact area. Due to the temperature difference and phase transformation of the nitrogen (from liquid to gas), there is convective heat transfer from the tool to the nitrogen, resulting in a temperature decrease in the tool. The total heat capability is therefore the sum of the sensible heat transfer rate (Eq. (1)) and latent heat transfer rate, $Q_{1}^{\prime}$, in $W$ which is 
due to the phase transformation from liquid to gas, determined by:

$Q^{\prime} l=\cdot h e$

where $h_{e}$ is the latent heat of vaporization, in $\mathrm{J} / \mathrm{kg}$. On the other hand, $\mathrm{LCO}_{2}$ is stored and delivered into the cutting zone at an ambient temperature, e.g. $20^{\circ} \mathrm{C}(293.15 \mathrm{~K})$ and a pressure of $57 \mathrm{bar}$ (5.7 MPa). Due to the decrease of the saturation pressure upon exiting the nozzle, the $\mathrm{LCO}_{2}$ vaporizes and expands, absorbing heat from the surroundings. This is caused based on evaporation, JouleThompson and sublimation mechanisms. If the amount of $\mathrm{LCO}_{2}$ is sufficient, the micro-region is cooled down to the boiling point of $\mathrm{CO}_{2},-78.5^{\circ} \mathrm{C}(194.65 \mathrm{~K})$. Therefore, the total heat capability of $\mathrm{LCO}_{2}$ can be determined similarly as for $\mathrm{LN}_{2}[1,2,11]$. However, it must be noted that not all of the latent heat generated due to the phase transformation of $\mathrm{LN}_{2}$ or $\mathrm{LCO}_{2}$ is used to cool the cutting zone. Some portion is also consumed in the surroundings. The impact of the surrounding is visible in Fig. 1, where the temperatures of the emulsion, the $\mathrm{LN}_{2}$ and the $\mathrm{LCO}_{2}$ are measured (detailed explanation of the experimental setup in Section 3). Measurements were performed with thermocouples placed just before entering and when leaving the heating zone.

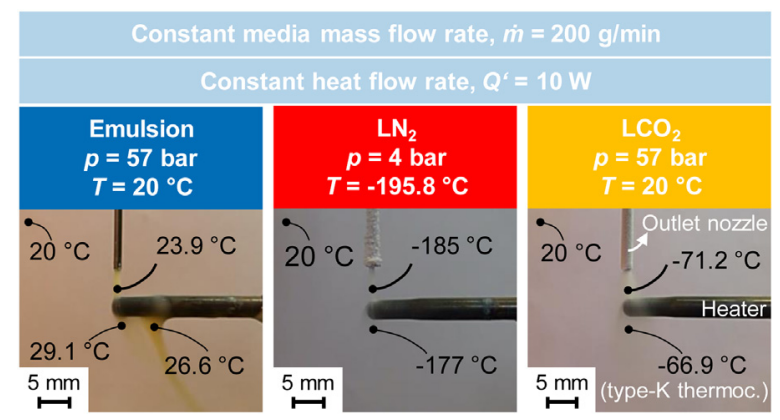

Fig. 1. Comparative temperatures of the media before cooling and right after leaving the hot zone of a controlled heat source.

\section{Fundamental experiments}

For the fundamental experiments, a unique experimental setup was developed, as shown in Fig. 2. A controlled heat source (heater) was used for constant heat generation simulating the heat generation in machining process. By varying the input power, in Watts, different rates of heat generation were achieved. Furthermore, the temperature inside the heater was monitored using an integrated type-K thermocouple with a sampling rate of $200 \mathrm{~ms}$. The emulsion, $\mathrm{LN}_{2}$ and $\mathrm{LCO}_{2}$ were delivered to the heater via an outlet nozzle with the diameter of $d=0.8 \mathrm{~mm}$. The heat-source power was varied in order to achieve controlled heater temperatures of $50^{\circ} \mathrm{C}(323.15 \mathrm{~K}), 80^{\circ} \mathrm{C}(353.15 \mathrm{~K}), 100^{\circ} \mathrm{C}(373.15 \mathrm{~K})$ and $200{ }^{\circ} \mathrm{C}(473.15 \mathrm{~K})$. In this way, the cooling capability of a delivered media is directly correlated to the heat transfer rate of the heater.
Afterwards, the maximal cooling rate of the media was determined by observing the temperature drop of heater from $100^{\circ} \mathrm{C}$ $(375.15 \mathrm{~K})$, when the heater was turned OFF. The derivative of temperature signals have been analyzed in time and the maximal cooling rate has been calculated as average of five points of derivative, where maximum exists. An emulsion with a 7\% concentration was supplied using a high-pressure (HP) pump from the emulsion tank of the machining center under the same temperature and pressure as the $\mathrm{LCO}_{2}$, which was stored in a bottle at $20^{\circ} \mathrm{C}(293.15 \mathrm{~K})$ and $57 \mathrm{bar}(5.7 \mathrm{MPa}) . \mathrm{LN}_{2}$ was supplied from the Dewar under a pressure of 4 bar $(0.4 \mathrm{MPa})$ and temperature of $-195.8^{\circ} \mathrm{C}(77.35 \mathrm{~K})$.The mass flow rate of all the media was set constant during each experiment. Experiments were performed for two different flow levels: 100 and $200 \mathrm{~g} / \mathrm{min}$, determined from Refs. [7,12]. The emulsion and $\mathrm{LCO}_{2}$ mass flow rates were controlled using a precision needle valve and Coriolis mass flow meter. For the $\mathrm{LN}_{2}$ mass flow rate control, a weighting of the Dewar and a proprietary SUSCRYMAC delivery system were used. All experiments utilized the same outlet nozzle with an inner diameter of $0.8 \mathrm{~mm}$. The nozzle was positioned $5 \mathrm{~mm}$ from the heater, which represents a comparable distance between the exit nozzle and the cutting insert of the milling tool used for the milling experiments in this study (presented in Section 4). The center of the outlet nozzle was aligned with the center of the heater, which is $1 \mathrm{~mm}$ from the heater's edge, as shown in Fig. 2. Furthermore, two nozzle angles were investigated: (a) Nozzle position A with a projection angle of $60^{\circ}$ was selected in order to exclude the impact of the wettability of the medium on the heater's surface, as performed in Ref. [13], and (b) orthogonal Nozzle position B with a projection angle of $90^{\circ}$, which was found by Refs. $[1,14]$ to be the most effective for cooling. For the sake of repeatability, each experiment was repeated 4 times.

Fig. 3 shows the cooling heat transfer rates of emulsion, $\mathrm{LN}_{2}$ and $\mathrm{LCO}_{2}$. It is evident that the cooling capability of emulsion, $\mathrm{LN}_{2}$ and $\mathrm{LCO}_{2}$ increases with increasing media mass flow rate. For experiments with nozzle position $\mathrm{A}\left(60^{\circ}\right.$ projection angle), the cooling capability of $\mathrm{LN}_{2}$ and $\mathrm{LCO}_{2}$ - with the same mass flow rate is comparable. However, due to its higher heat of vaporization, $\mathrm{LCO}_{2}$ has a slightly higher cooling heat-transfer rate than $\mathrm{LN}_{2}$. In addition, the heat evacuation mechanism of $\mathrm{LN}_{2}$ and $\mathrm{LCO}_{2}$ is mainly dependent on their phase transformation and heat absorption, therefore, the cooling capability of $\mathrm{LN}_{2}$ and $\mathrm{LCO}_{2}$ slowly increases with an increase in workpiece temperature and is mainly conditioned by the media flow rate. Knowing this, it can be seen, that with a controlled media mass flow rate, the cutting temperature can be controlled or even optimized [15]. In contrast, the heat-evacuation mechanism of emulsion is mainly dependent on the temperature difference, meaning that the cooling capability of emulsion increases when a higher heat-transfer rate is generated on the heater. Therefore, the cooling capability of emulsion at a lower workpiece temperatures is reduced, compared to the cooling capabilities of $\mathrm{LN}_{2}$ and $\mathrm{LCO}_{2}$. Similar findings can be observed when experimenting with an orthogonal nozzle position

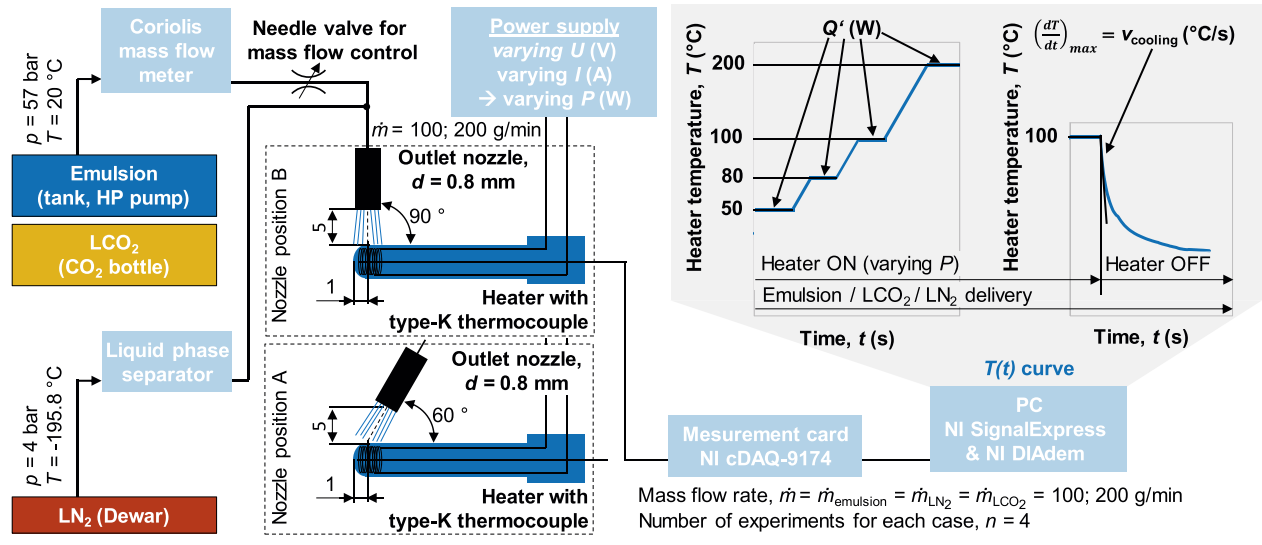

Fig. 2. Illustration of the experimental setup for fundamental experiments. 


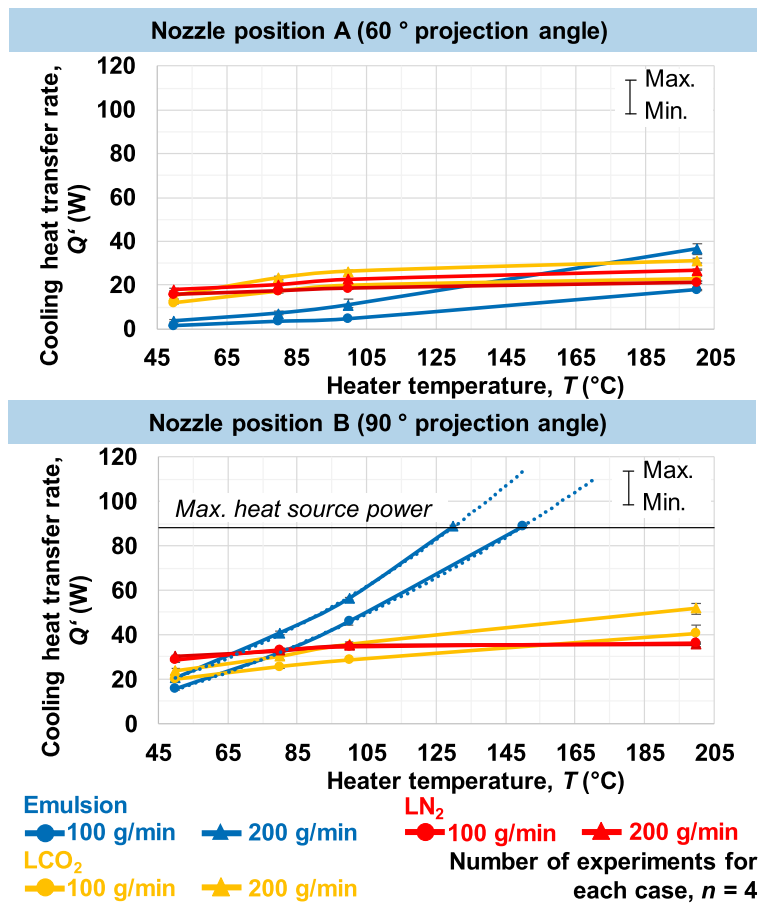

Fig. 3. Cooling heat transfer rates of emulsion, $\mathrm{LN}_{2}$ and $\mathrm{LCO}_{2}$.

$\mathrm{B}\left(90^{\circ}\right.$ projection angle). Here, due to the direct impact of the media onto the heater, an overall higher cooling capability of emulsion, $\mathrm{LN}_{2}$ and $\mathrm{LCO}_{2}$ can be observed. Similar trends have been observed in Refs. [1,14], where the authors found that the orthogonal orientation of the tool cooling channel relative to the cutting edge is the most effective for cooling of the cutting zone. In addition, good wettability is essential for effective cooling [16]. The emulsion remains in liquid phase during cooling, therefore it stays in contact with the heater's surface for a longer time. Moreover, it can be seen that the surface area affected by the emulsion is much larger that the area affected by $\mathrm{LN}_{2}$ or $\mathrm{LCO}_{2}$ (visible on Fig. 1). Therefore, the emulsion offers better overall bulk cooling in comparison to $\mathrm{LN}_{2}$ and $\mathrm{LCO}_{2}$. However, when considering the maximum cooling rates, similar results can be seen for emulsion, $\mathrm{LN}_{2}$ and $\mathrm{LCO}_{2}$ (Fig. 4).

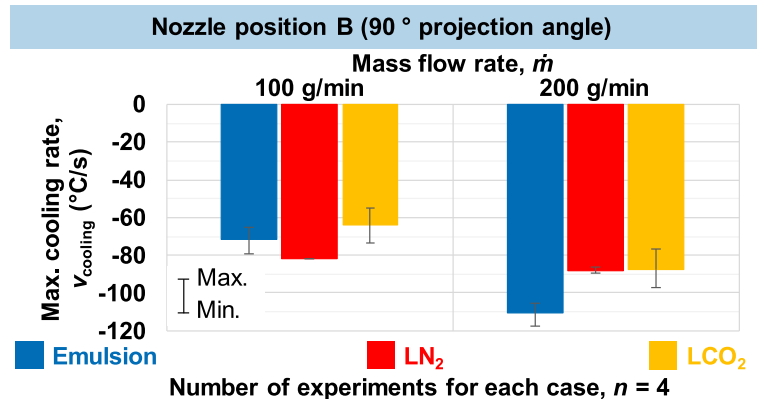

Fig. 4. Maximum cooling rates of emulsion, $\mathrm{LN}_{2}$ and $\mathrm{LCO}_{2}$.

\section{Milling experiments}

In order to verify the fundamental experiments, milling experiments using in-process cutting-temperature measurements were performed on two separate but comparable experimental setups. The first were performed on an industrial case study, while the second were performed with direct verification of the cooling fluid delivery principle used in the fundamental study. Titanium alloy Ti-6Al-4V in $\beta$ microstructure was used as the workpiece material with the cutting parameters: $v_{\mathrm{c}}=40 \mathrm{~m} / \mathrm{min}, f_{\mathrm{z}}=0.1 \mathrm{~mm}$, $a_{\mathrm{p}}=4 \mathrm{~mm}, a_{\mathrm{e}}=0.6 \times D \mathrm{~mm}$. For the sake of repeatability, each milling experiment was repeated two times.
A Mori Seiki Frontier M three-axis CNC vertical machining center was used to perform the milling experiments under conventional cooling with emulsion and cryogenic $\mathrm{LN}_{2}$ and $\mathrm{LCO}_{2}$ cooling. Emulsion ( $7 \%$ concentration) and $\mathrm{LCO}_{2}$ were supplied from inside the cutting tool through a nozzle with an $0.8 \mathrm{~mm}$ diameter under a pressure of $p=57 \mathrm{bar}(0.5 \mathrm{MPa})$ and temperature of $T=20^{\circ} \mathrm{C}(293.15 \mathrm{~K})$. Due to the low temperatures of $\mathrm{LN}_{2}$ and related problems (insulation, etc.), $\mathrm{LN}_{2}$ was supplied into the cutting zone from the Dewar via an outlet nozzle with a diameter of $d=0.8 \mathrm{~mm}$. Milling experiments were performed for two different media flow rates of $=100$ and $200 \mathrm{~g} / \mathrm{min}$, the media mass flow rate was controlled in the same way as in the fundamental experiments.

A special, tailor-made tool holder with an integrated rotary unit for through-the-tool delivery of coolant was developed. A singletooth milling cutter with a diameter of $D=10 \mathrm{~mm}$ with the appropriate CVD Ti(C,N)-coated tungsten-carbide insert was used. For the in-process cutting temperature measurements, a tailormade telemetry system with type-K thermocouple with a diameter of $d=0.5 \mathrm{~mm}$ integrated into the cutting insert was developed. The position of the thermocouple was at the tip of the tool, $0.1 \mathrm{~mm}$ from the rake face.

The telemetry system consists of a stationary part and a rotary part. The stationary part is used to provide an inductive power supply to the rotary part, to which the thermocouple is connected and rotates together with the cutting tool. Wireless transmission was used for the temperature data-transfer from the rotary part to a computer application that records data with a sampling rate of $20 \mathrm{~ms}$. The second set of temperature measurements in milling process, using industrial state-of-the-art conditions of cooling with emulsion, were also performed and compared to the temperatures in $\mathrm{CO}_{2}$-assisted machining. In this case, emulsion was supplied under a pressure of $p=5$ bar $(0.5 \mathrm{MPa})$ from the outside via an outlet nozzle with the diameter of $5 \mathrm{~mm}$ into the cutting zone with a corresponding volumetric flow rate of $\dot{V}=33.6 \mathrm{~L} / \mathrm{min}$. These experiments were performed on an ExCell-O XHC 241 four-axis CNC horizontal machining center with a 4-cutting-edge, $D=40 \mathrm{~mm}$, milling cutter of the type Cryo.tec ${ }^{\circledR}$ F4042.6903229 provided by WALTER TOOLS. The identical CVD Ti (C,N)-coated tungsten-carbide inserts and K-type thermocouple, integrated into one cutting insert, were used, as shown in Fig. 5. The $\mathrm{LCO}_{2}$ mass flow rate was controlled by an AEROSOL MASTER 4000 cryolub $^{\circledR}$ system of ROTHER TECHNOLOGIE and a Coriolis mass flow meter. While in this case the temperature measurement data were transferred via a wireless FM/PCM transmitter produced by MANNER SENSORTELEMETRIE. The thermoelectric voltage of the thermocouple was recorded with a sample rate of $6620 \mathrm{~Hz}$. Further details are presented in Ref. [17].

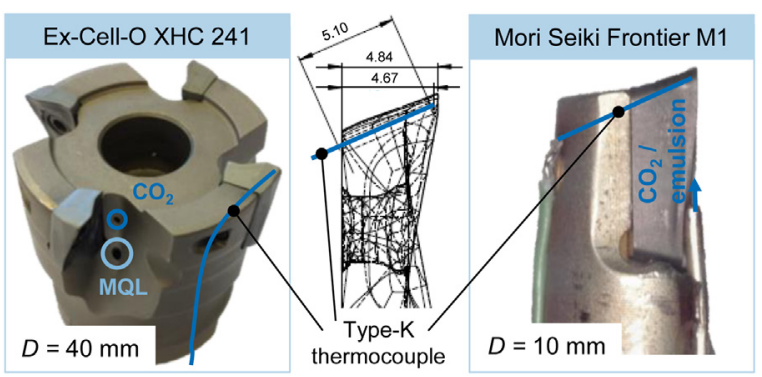

Fig. 5. Cutting tools with embedded type-K thermocouples used in milling experiments.

The results from both verification milling experiments are shown in Fig. 6. Observing the temperature results obtained during milling of titanium alloy Ti-64Al-4V (ß) under different cooling conditions, comparable trends can be observed, even when correlating them with temperature measurements in fundamental experiments with cooling of a known heat source. Cutting temperatures are inversely proportional to the cooling capability/cooling heat-transfer rate and the mass flow rate of a given media, i.e., the cutting temperature achieved in the presence of the 


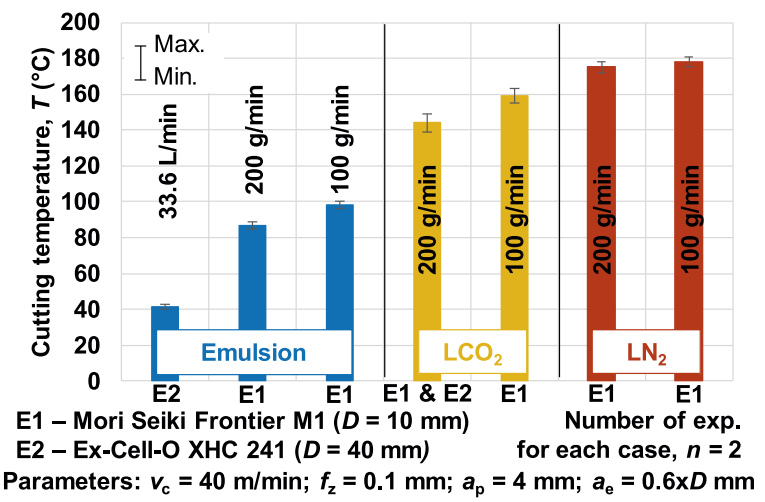

Fig. 6. Cutting temperatures during milling of titanium alloy Ti-6Al-4V $(ß)$ under different cooling conditions.

coolant with a higher cooling capability will be lower. In addition, a higher mass flow rate of a coolant will result in a lower cutting temperature. As shown in Section 3, emulsion provides better cooling capability than cryogenic media and therefore, the lowest cutting temperature was achieved under cooling with emulsion, followed by cooling with $\mathrm{LCO}_{2}$ and $\mathrm{LN}_{2}$, respectively. It was found that, when using media mass flow rates of $=100$ and $200 \mathrm{~g} / \mathrm{min}$, emulsion provides, on average, $92 \%$ and $64 \%$ better cooling (higher heat transfer rate) compared to $\mathrm{LN}_{2}$ and $\mathrm{LCO}_{2}$, respectively. However, from our previous work, it has been shown that, even though the temperatures of the process are lower with using emulsion, using $\mathrm{LCO}_{2}$ in combination with MQL in milling yields longer tool life in comparison to cooling with emulsion [12]. This indicates that there exists an optimal cutting temperature which produces the longest tool life: too low of a temperature can result in a shorter tool life. Therefore, the coolant flow rate has to be controlled and optimized.

\section{Conclusions}

Cooling capabilities of $\mathrm{LN}_{2}$ and $\mathrm{LCO}_{2}$ were experimentally assessed by measuring in-process temperatures during fundamental heat-transfer test and verified during milling of titanium alloy Ti-6Al-4V (ß). Main findings are the following:

- The cooling capability of emulsion, $\mathrm{LN}_{2}$ and $\mathrm{LCO}_{2}$ increased with increasing media mass flow rate.

- The coolant outlet nozzle orientation has a significant effect on a media's cooling capability. The most effective nozzle orientation is orthogonal to the heat source.

- The heat-evacuation mechanism of $\mathrm{LN}_{2}$ and $\mathrm{LCO}_{2}$ mainly depends on the heat absorption due to the phase transformation of the cryogen.

- Heat evacuation with emulsion is mainly dependent on the temperature difference, meaning that its cooling capability increases with heat generation, in contrast to the cryogenic media. This is because the emulsion remains in the liquid state during cooling, and therefore stays in contact with the heater or workpiece surface for a longer time.

- Cutting temperature measurements coupled with tool life experiments indicate that there exists an optimal cutting temperature that can be achieved by sufficient mass flow rate of a coolant.

\section{Acknowledgements}

This research was partially supported by Slovenian Research Agency (ARRS) founded research project L2-8184 and research program P2-0266. Additionally founding was provided by the research project "InKryo" (IGF 19122 N) of the German Machine Tool Builder's Association (VDW) which is supported by Federal Ministry for Economic Affairs and Energy within the program "Industrial Collective Research for SME's" (IGF) via German Federation of Industrial Research Associations (AiF).

\section{References}

[1] Jawahir IS, Attia H, Biermann D, Duflou J, Klocke F, Meyer D, Newman ST Pušavec F, Putz M, Rech J, Schulze V, Umbrello D (2016) Cryogenic Manufacturing Processes. Annals of the CIRP 65:713-736.

[2] Çengel YA, Boles MA (2006) Thermodynamics: An Engineering Approach, 5th ed. McGraw Hill, New York.

[3] Rotella G,Umbrello D (2014) Finite Element Modeling of Microstructural Changes in Dry and Cryogenic Cutting of Ti6Al4V Alloy. Annals of the CIRP 63:69-72.

[4] Hong SY, Ding Y (2001) Cooling Approaches and Cutting Temperatures in Cryogenic Machining of Ti-Al-4V. International Journal of Machine Tools and Manufacture 41(10):1417-1437.

[5] Hriberšek M, Šajn V, Pušavec F, Rech J, Kopa J (2016) The Procedure of Solving the Inverse Problem for Determining Surface Heat Transfer Coefficient Between Liquefied Nitrogen and Inconel 718 Workpiece in Cryogenic Machining. Strojniški vestnik - Journal of Mechanical Engineering 62(6):331-339.

[6] Lequien P, Poulachon G, Outeiro JC, Rech J (2018) Hybrid Experimental/Model ling Methodology for Identifying the Convective Heat Transfer Coefficient in Cryogenic Assisted Machining. Applied Thermal Engineering 128:500-507.

[7] Cordes S, Hübner F, Schaarschmidt T (2014) Next Generation High Performance Cutting by Use of Carbon Dioxide as Cryogenics. 6th CIRP International Conference on High Performance Cutting (HPC) - Procedia CIRP 14:401-405.

[8] Mulyana T, Rahim EA, Yahaya SNM (2017) The Influence of Cryogenic Supercritical Carbon Dioxide Cooling on Tool Wear During Machining High Therma Conductivity Steel. Journal of Cleaner Production 164:950-962.

[9] Rahim EA, Rahim AA, Ibrahim MR, Mohid Z (2016) Experimental Investigation of Supercritical Carbon Dioxide $\left(\mathrm{SCCO}_{2}\right)$ Performance as a Sustainable Cooling Technique. 13th Global Conference on Sustainable Manufacturing - Decoupling Growth from Resource Use - Procedia CIRP 40:637-641.

[10] Jerold BD, Kumar MP(2012) Experimental Comparison of Carbon-Dioxide and Liquid Nitrogen Cryogenic Coolants in Turning of AISI 1045 Steel. Cryogenics 52:569-574.

[11] Busch K, Hochmuth C, Pause B, Stoll A, Wertheim R(2016) Investigation of Cooling and Lubrication Strategies for Machining High-Temperature Alloys. 48th CIRP Conference on Manufacturing Systems (CMS) - Procedia CIRP 41:835-840.

[12] Bergs T, Pušavec F, Koch M, Grguraš D, Döbbeler B, Klocke F (2018) Investigation of the Solubility of Liquid $\mathrm{CO}_{2}$ and Liquid Oil to Realize an Internal Single Channel Supply in Milling of Ti6Al4V. 16th Global Conference on Sustainable Manufacturing (GCSM) - Procedia Manufacturing, . Accepted for publication.

[13] Sales WF, Guimaraes G, Machado AR, Ezugwu EO (2002) Cooling Ability of Cutting Fluids and Measurement of the Chip-Tool Interface Temperatures. International Lubrication and Tribology 54(2):57-68.

[14] Stoll A (2014) Entwicklung einer ressourceneffizienten Frästechnik mit kryogener Kühlung (in German), Colloquium blueS "Ressourceneffiziente Fertigungssysteme und Technologien", Chemnitz. Available from: http://publica.fraunhofer. de/eprints/urn_nbn_de_0011-n-3091553.pdf. (Accessed January 2019).

[15] Isakson S, Sadik MI, Malakizadi A, Krajnik P (2018) Effect of Cryogenic Cooling and Tool Wear on Surface Integrity of Turned Ti-6Al-4V. 4th CIRP Conference on Surface Integity (CSI) - Procedia CIRP 71:254-259.

[16] Kumar KM, Ghosh A (2016) Assessment of Cooling-Lubrication and Wettability Characteristics of Nano-Engineered Sunflower Oil as Cutting Fluid and Its Impact on SQCL Grinding Performance. Journal of Materials Processing Technology 237:55-64.

[17] Augspurger Thorsten, Koch Matthias, Klocke Fritz, Döbbeler Benjamin (2019) Investigation of transient temperature fields in the milling cutter under $\mathrm{CO}_{2}$ cooling by means of an embedded thermocouple. Procedia CIRP 79:33-38. 